\title{
THE PHOTOSENSITIVE PIGMENTS IN THE RETINAE OF DEEP-SEA FISH
}

\author{
E. J. Denton and F. J. WARRen \\ The Plymouth Laboratory
}

(Text-figs. I and 2)

The deep-sea fishes might be expected to have eyes specialized for their environment because this differs in some striking respects from that of terrestrial and shallow water animals. The groups of mid-water oceanic fish on which most of these experiments were made live in the 'twilight' zone of the ocean. Here daylight, much attenuated by the sea water through which it has passed, is blue-green in colour, and the light given by the luminescent organs of animals is an important fraction of the total light available (Clarke \& Wertheim, 1956). These animals probably have two visual tasks, the first that of perceiving the daylight above by which they must regulate their daily vertical migrations, and second seeing the small flashing photophores of other animals or the small shadows of other animals against daylight which serve to guide them to their food and their mates and to warn them of the presence of enemies. These two tasks do not demand the same kind of eye.

To see small spots of light efficiently a large collecting pupil is needed, and a large eye such as the eye of an oceanic squid, provided that it can form a good image, will have very distinct advantages over a small one. To see a very large field such as that given by the daylight coming through sea water the size of the eye is not important, but only the aperture, i.e. a relationship between size of pupil and the other dimensions of the eye. But whatever the structure and use of the eye the efficiency with which the retina absorbs the light quanta incident on it will be of the first importance. The light penetrating oceanic waters best is blue-green in colour, and the deeper the ocean is penetrated the more and more the penetrating light becomes confined to a narrow band of wavelengths around $475 \mu$ (Jerlov, 1947-8). This fact has suggested to Marshall (1954) that the eyes of deep-sea fish would be especially sensitive to such blue light, a prediction which has been borne out by experiment (Denton \& Warren, I956).

\section{METHODS}

The eyes of many deep-sea fish are quite small and are not in general available in such numbers as to make the classical methods of extraction useful. The measurements were therefore made on intact retinae using new methods 
described in detail elsewhere (Denton \& Wyllie, 1955; Denton, 1954; Denton \& Walker, 1957) which demand only very small areas of retina. Such methods have the added advantage of giving directly the density of pigment in the retina, a quantity essential to an evaluation of the possible sensitivity of the eye. The method is briefly as follows: (I) Under Ringer's solution the retina is dissected from the dark adapted eye. It is floated rod-side uppermost into a chamber made by fixing a ring of wax on to a microscope slide and then, after filling with Ringer's solution, this chamber is closed with a cover glass. (2) An image of the retina is thrown by a $\frac{2}{3}$ in. objective on to a diaphragm and the retina moved until the image of a uniform part of the retina in which the rods are upright is seen to fall on the hole in the diaphragm. The eye of the observer is replaced by a photomultiplier tube which thus collects light which has passed through one thickness of a small area of retina. (3) The colour and intensity of the light reaching the retina can be changed by neutral and colour filters placed between the light source and the substage condenser of the microscope. The output of the photomultiplier is measured with a Cossor oscillograph (Model I049). (4) Measurements are made for a series of colour filters both before and after bleaching the retina with strong white light. The assumption is made (Denton \& Walker, 1957) that the retina contains no photosensitive pigment appreciably absorbing deep red light of wavelength about $650 \mathrm{~m} \mu$, and that this light can be used as a reference light showing changes in sensitivity of the light source and recording system. Corrections are thus calculated which are used for measurements with other colour filters. The apparatus is very robust and, since the measuring instrument is virtually without inertia, it can be used aboard ship without any special difficulty. The apparatus was not appreciably disturbed by the movement of the ship in any but the heaviest seas.

\section{MATERIAL}

The experiments were made on freshly caught deep-sea fish; some aboard R.V. Sarsia, and others aboard R.R.S. Discovery II. Aboard R.V. Sarsia the fish were caught in the Bay of Biscay off the continental shelf by verticals hauls made from $2000 \mathrm{~m}$ with a $2 \mathrm{~m}$ stramin ring trawl. Aboard R.R.S. Discovery II the fish were caught in an Isaacs Kidd mid-water trawl fished at various depths estimated at being between 200 and $1500 \mathrm{~m}$. The catch was generally brought up either at twilight or after dark and care taken not to expose the fish used for experiments to bright lights. Some of the fish used were alive when brought to the surface but others were dead. Since the haul with the Isaacs Kidd trawl was generally for $4 \mathrm{~h}$ it is possible that some fish had been dead for $4 \mathrm{~h}$ before experiments were begun. 


\section{RESULTS}

\section{EFFECT OF TIME ON THE DIFFERENCE CURVE}

On bleaching a retina by exposing it to a bright light a chain of reactions is started which continues in the dark. These reactions were first described by Kühne (1878) in his classical work on visual purple. The retina of the frog, which Kühne used extensively, is rose pink in colour when unbleached and passes, following exposure to a bright light, through orange and yellow to become finally colourless. Similarly, following bleaching, the photosensitive pigments in the retinae of deep-sea fish, which are all golden in colour when unbleached, undergo a series of reactions in which the products have absorption spectra displaced progressively farther towards the ultra-violet. This is shown in Figs. I A and B, in which difference curves (a difference curve shows the change in density between unbleached and bleached retinae as a function of wavelength) at various times following bleaching are given. No matter how long a time is given after bleaching, the products of bleaching are always appreciably more heavily absorbing in the deep blue and near ultra-violet than the unbleached pigment from which they were formed. This is very characteristic of this group of golden pigments. Rhodopsin and porphyropsin pigments in the intact retina usually give products of bleaching in which the absorption in the deep blue and near ultra-violet is very like, or less, than that of the unbleached pigment.

For the deep-sea fish the dark reactions go on very slowly after the first hour following bleaching. Most of the difference curves given here are of difference in density between an unbleached retina and the retina an hour after bleaching.

\section{EFFECT OF TIME AFTER DEATH OF THE ANIMAL AT WHICH MEASUREMENTS ARE BEGUN}

To find the possible effect of the death of an animal for a period of $4 \mathrm{~h}$ before observations are made ( $4 \mathrm{~h}$ was the time of a typical haul), measurements were made on the retinae of a Chauliodus sloanei which was caught alive. One retina was dissected and used immediately after death, whilst the other retina was dissected and used $4 \mathrm{~h}$ later. Fig. I C shows that the difference curves are very similar except that the dark reactions following bleaching have gone less far in the later preparation. The consequent distortion of the curve is very slight over most of the visual spectrum and insufficient to displace the wavelength of maximum difference in density.

The maximum density change on bleaching was smaller for the 'older' preparation. The maximum density change for the first retina being 0.67 and of the second 0.40 . It was the rule in these experiments that high retinal densities were always found in those fish caught alive. 


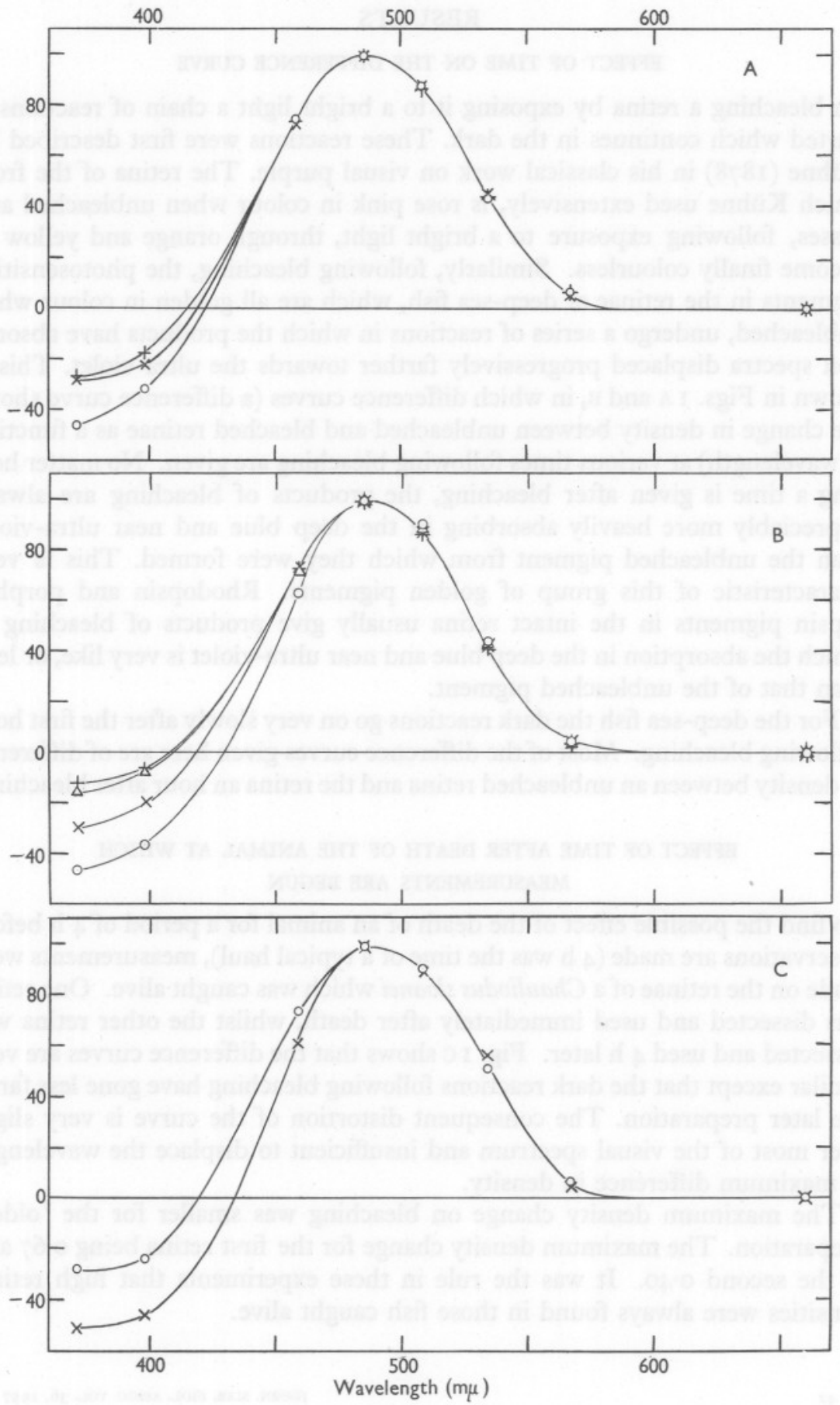

Fig. I 


\section{DENSITY OF PIGMENT}

The density change on bleaching was measured for all the preparations used (Table I). The maximum density change was always for light of wavelengths around $485 \mathrm{~m} \mu$. When the measurements were completed it was always possible to see the small area of colourless bleached retina in the otherwise golden-coloured retina, and thus confirm that only one thickness of retina had been used for the measurements on which the density change is based.

TABLE 1. DENSITY CHANGE ON BLEACHING FOR LIGHT OF WAVELENGTH $485 \mathrm{M} \mu$

\begin{tabular}{|c|c|c|}
\hline Family & Species & Max. density change \\
\hline Melamphaidae & Melamphaës megalops Lütken & 0.19 \\
\hline & Melamphaës unicornis Gilbert & 0.56 \\
\hline Synaphobranchidae & Synaphobranchus kaupi Johnson & 0.27 \\
\hline Sternoptychidae & Argyropelecus hemigymnus Сocco & $\mathrm{I} \cdot 08$ \\
\hline " & Argyropelecus aculeatus C.V. & $I \cdot 20^{\star}$ \\
\hline & Argyropelecus olfersii (Cuvier) & 0.78 \\
\hline Chauliodontidae & Chauliodus sloanei sloanei Schneider & $\begin{array}{l}0.67 \\
0.46\end{array}$ \\
\hline Myctophidae & Lampanyctus ater Tåning & 0.31 \\
\hline , & Diaphus rafinesquei (Cocco) & 0.43 \\
\hline , & Lampadena braueri Zugmayer & $0.2 I^{\star}$ \\
\hline ” & Myctophum punctatum Rafinesque & $0.4 \mathrm{I}$ \\
\hline Gonostomatidae & Gonostoma elongatum Günther & I.OI \\
\hline Searsidae & Searsia sp. & I. 2 I \\
\hline Diretmidae & Diretmus argenteus Johnson & $0.98^{\star}$ \\
\hline Argentinidae & Opisthoproctus soleatus Vaillant & 0.54 \\
\hline Stomiatidae & Stomias boa (Risso) & 0.79 \\
\hline Melanostomiatidae & Flagellostomias sp. & 0.58 \\
\hline
\end{tabular}

* For these retinae only the density change at $485 \mathrm{~m} \mu$ was measured and not the difference curve.

To these we may add Conger vulgaris, 0.58 (see Denton \& Walker, 1957). Of the oceanic fish examined only one, a surface-living fish, Scombresox saurus, had a rose-coloured retina. The maximum density change for its retina was at $508 \mathrm{~m} \mu$ and was 0.60 and the difference curve typical of the coastal fish.

\section{SHAPE OF ABSORPTION CURVES}

Parts of all retinae were examined visually in white light. All were found to have golden-coloured pigments except the gar fish (Scombresox saurus), which was rose-coloured, and the myctophid Diaphus rafinesquei (Cocco), which was

\section{Legend to Fig. I}

Fig. I. Curves show difference in density between unbleached and bleached retina plotted against wavelength. The maximum fall in density on bleaching is made equal to $100 \%$. A, Argyropelecus hemigymnus Cocco: $\bigcirc-0,4-20$ min after bleaching; $\times-\times, 35-45 \mathrm{~min}$.

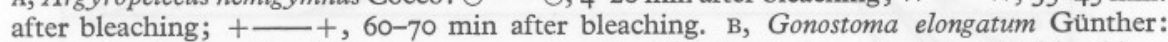
$\bigcirc-\mathrm{O}, \mathrm{I} \mathrm{h}$ after bleaching; $\times-\times, 2 \mathrm{~h}$ after bleaching; $\triangle-\Delta, 6 \mathrm{~h}$ after bleaching; ,$+-+ 24 \mathrm{~h}$ after bleaching. c, Chauliodus sloanei sloanei Schneider, showing the effect of death of animal on the density difference curve between unbleached and bleached retina. The measurements on bleached retina were made $\mathrm{I} \mathrm{h}$ after bleaching. $\mathrm{-}-\mathrm{O}$, retina dissected immediately after death; $\times-\times$, retina dissected $4 \mathrm{~h}$ after death. 

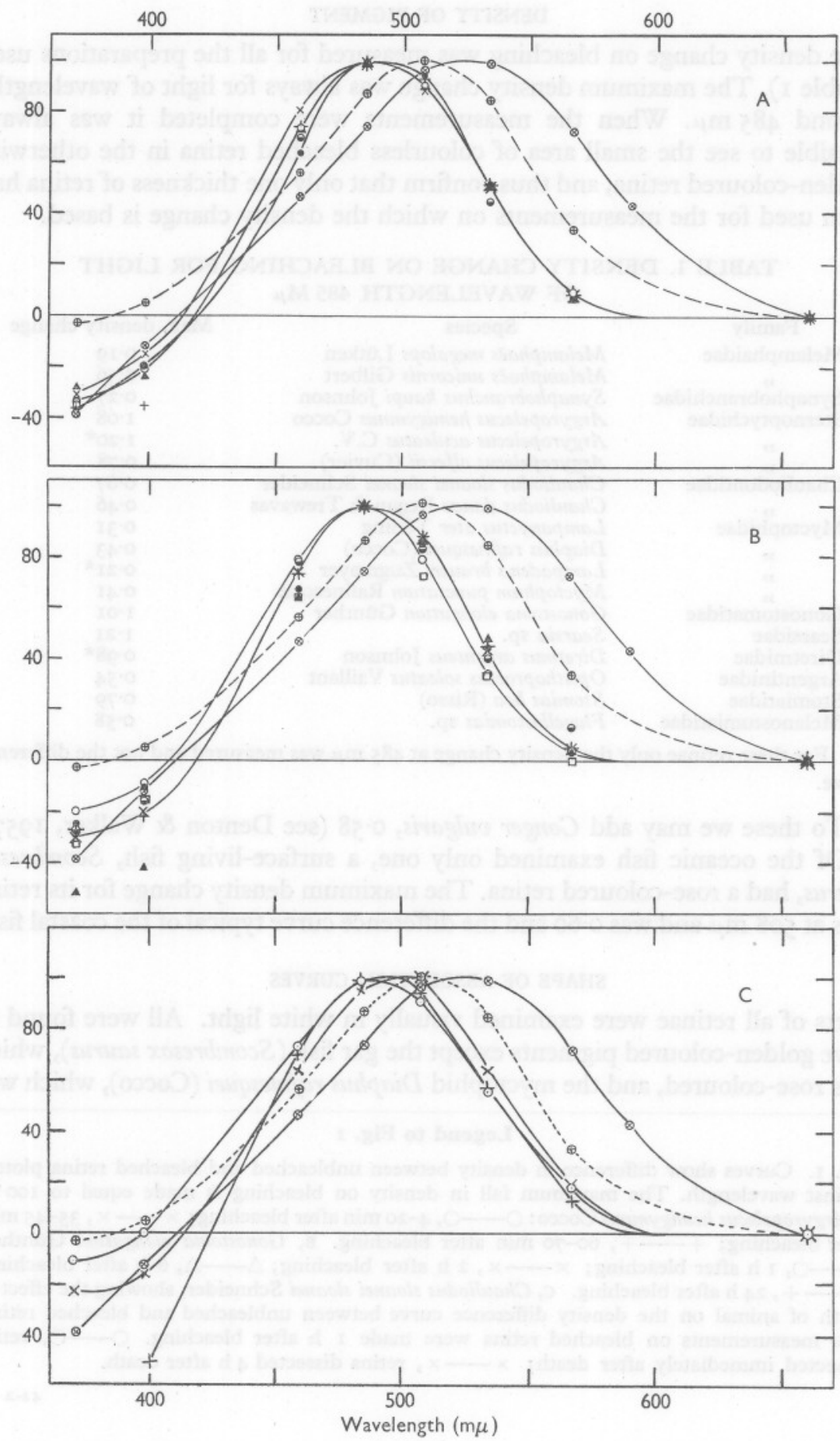

Fig. 2 
noted as having a colour intermediate between that of the conger and the gar-fish, and was later found to give an absorption curve that fell between those for these two fish.

The results for the fish are plotted in three groups: (I) the difference curve very closely resembles that of the conger eel (Fig. 2A); (2) the maxima of absorption are displaced a little farther towards the blue than the conger eel (Fig. 2B); (3) the maxima of absorption are displaced a little farther towards the red than the conger eel (Fig. 2C).

One other species, Argyropelecus aculeatus C.V., was examined visually and found to have a golden-coloured retina, but absorption curves were not measured on it.

\section{DISCUSSION}

A good number of visual photosensitive pigments are now known and recent work, particularly by Dartnall and his collaborators, has shown that the types of scotopic visual pigments are more varied than was at first thought. The broad generalization, however, made by Wald (1945-6) that freshwater fish have retinae containing principally purple-coloured pigments (porphyropsins), whilst the coastal marine fish have retinae containing principally rosecoloured pigments (rhodopsins) remains substantially true. As a result of the present experiments it seems likely that the great majority of deep-sea fish, if not all, have retinae containing principally golden-coloured pigments and thus form a third great grouping. Denton \& Warren (1956) have suggested the names chrysopsins or visual golds for these golden-coloured pigments. On the basis of the experiments described here we cannot eliminate the possibility that some of these golden-coloured retinae contain mixtures of pigments. [Miss M. A. Walker (private communication) finds that a digitonin extract of the retinae from six Diaphus rafinesquei (Cocco) caught in the same haul as the one used in the experiment described above, contained in fact only one photosensitive pigment.]

The difference curves shown in Fig. 2 for deep-sea fish differ from those measured on rhodopsin and porphyropsin retinae in that the increase in density

\section{Legend to Fig. 2}

Fig. 2. Curves showing density difference between unbleached and bleached retinae plotted against wavelength. The maximum fall in density for each retina is made equal to $100 \%$. A, Curves for the following species: $\mathrm{O}-\mathrm{O}$, Conger conger; $\times-\times$, Myctophum punctatum Rafinesque; +, Flagellostomias sp.; - Melamphaës megalops Lütken; $\mathbf{\Delta}$, Chauliodus sloanei sloanei Schneider; $\odot$, Opisthoproctus soleatus Vaillant. For comparison: $\oplus---\oplus$, Cottus bubalis; $\otimes-\otimes$, sea trout. B, Curves for the following species: $\bigcirc-\bigcirc$, Argyropelecus olfersii (Cuvier); +, Argyropelecus hemigymnus Cocco; $\times-\times$, Gonostoma elongatum Günther;

$\mathbf{\Delta}$, Chauliodus danae Regan \& Trewavas; $\bullet$, Melamphaës unicornis Gilbert; $\bullet$, Searsia sp.; $\mathbf{\mathbf { v }}$, Synaphobranchus kaupi Johnson. For comparison: $\oplus--\oplus$, Cottus bubalis; $\otimes-\otimes$, sea trout. c, Curves for the following species: $\bigcirc-\bigcirc$, Lampanyctus ater Tåning; +Stomias boa (Risso); $\times-\times$, Diaphus rafinesquei (Cocco). For comparison: $\oplus-.-\oplus$, Cottus bubalis; $\otimes-\otimes$, sea trout. 
on bleaching for wavelengths between 380 and $400 \mathrm{~m} \mu$ is much greater. This characteristic, which they share with the conger eel and the silver freshwater eel (Carlisle \& Denton, unpublished observations) and which must represent a difference in the course of the dark reactions following bleaching, gives another reason for grouping the pigments of these fish together.

Wald (I938-9) has shown that the colour of the principal retinal photosensitive pigment of a freshwater or coastal marine fish is correlated with the fishes' enviroment (more exactly that in which it spawns) rather than with its family affiliations. Here again, for the deep-sea fish, we find fishes of the most varied appearance, habits and families sharing the characteristic of golden-coloured retinae, a property which they share with no other vertebrates so far studied.

\section{The limit to the depth at which daylight could be detected}

The known ways of assessing the sensitivity of an animal's eye, that of studying the animal's behaviour or by recording the change in nervous activity of the eye when lights are flashed into it, are not easily used on deep-sea fish, which are difficult to keep alive for more than a few hours and then only aboard a ship whose movements would make electrophysiological recording almost impossible. Even when such methods can be used it is difficult to be sure that behavioural responses are really made at the limit of the animal's sensitivity or that electrophysiological recordings are made from the most sensitive receptor and nervous elements. In this paper the method of approach is that of comparing the eyes of the deep-sea fish with our own and trying to assess what advantages and disadvantages may be given to them by any peculiarities of their eyes in the particular environment in which they live. Clarke (1936) has made estimates of the same type using the known sensitivity of the sun-fish (Lepomis) as the starting-point for his calculations.

Clarke \& Wertheim (1956) give the energy of penetrating daylight at $610 \mathrm{~m}$ (the remaining daylight will effectively all be of wavelength around $475 \mathrm{~m} \mu$ ) as $10^{-6} \mu \mathrm{W} \mathrm{cm}{ }^{2}$, which corresponds to a flux of $10^{-5} \mathrm{ergs} / \mathrm{sec} / \mathrm{cm}^{2}$. The incident flux required at the eye for the human just to see a large uniform field of this wavelength is given by Denton \& Pirenne (I954) as $10^{-7} \mathrm{ergs} / \mathrm{sec} / \mathrm{cm}^{2}$ of retina, or approximately $4 \times 10^{-7} \mathrm{ergs} / \mathrm{sec} / \mathrm{cm}^{2}$ at the pupil. This would imply that at $610 \mathrm{~m}$ in sunlight, in the part of the ocean where Clarke \& Wertheim made their measurements, the penetrating sunlight for an observer looking upwards would be about $\times 25$ above threshold. The oceanic waters of Clarke $\&$ Wertheim reduced penetrating daylight (at these depths only blue-green light is left) to about 10\% for approximately every $120 \mathrm{~m}$ and the absorption of oceanic water would, therefore, set the depth at which daylight could just be detected by the human eye at about $950 \mathrm{~m}$. The value given by direct observation by Beebe (1935) is about $550 \mathrm{~m}$, but this refers to daylight in a horizontal sense since the windows of his bathysphere faced towards its side. 
Light cannot be effective for vision unless it is absorbed by the photosensitive pigments of the retina, and in this respect the eyes of the deep-sea fish probably have considerable advantages over our own. These include (I) the pupils of deep-sea fish are, relative to the other dimensions of the eye, very much larger than human pupils. For the conger we can easily calculate (see Le Grand, 1948) that the gain in retinal illumination due to this factor is about $\times 2.5$. It would be difficult to calculate the gains for some fish, e.g. Chauliodus sloanei, because the crystalline lens does not fill the pupil, but we can easily show that even an eye with no dioptric system and with light falling directly on to the photosensitive surface the gain would be $\times 5$, and this is the maximum possible gain. (2) The eye media of the human eye absorb about $50 \%$ of light of $500 \mathrm{~m} \mu$ as it passes from the cornea to the retina. This absorption will almost certainly be much less in the eye media of deep-sea fish because the lenses can be seen to be very transparent and the eyes are very much smaller than human eyes. This may give the deep-sea fish a gain of $\times 2$ in retinal illumination over the human. (3) The density of retinal photosensitive material is usually very much greater in the deep-sea fish than the human. Rushton (1956) gives the human retinal density of rhodopsin for light of $500 \mathrm{~m} \mu$ as about 0.15 , while we find that retinal densities of $\mathrm{I} \cdot 0$ or more are not uncommon in deep-sea fish. This will mean that the human retina will absorb about $30 \%$ of blue-green light incident on it whilst the deep-sea fish will absorb about $90 \%$ of blue-green light incident on it, thus giving the deep-sea fish a gain of $\times 3$ over the human.

Taking these three factors we may suppose that if a deep-sea fish and a human were both looking at the same large field of blue-green light, the number of quanta absorbed $/ \mathrm{cm}^{2}$ of retina/sec would be between I5-30 times greater for a deep-sea fish than for the human.

This suggests that if man and deep-sea fish are equally efficient at extracting information from absorbed quanta, then the deep-sea fish would see daylight at depths between I30 and I $70 \mathrm{~m}$ deeper than could man. This would put the maximum depth at which it could see daylight at about $1100 \mathrm{~m}$.

Light of a given wavelength can only be absorbed in packets of energy corresponding to the energy $h v$ of the quantum of that wavelength ( $h$ is Planck's constant and $v$ is the frequency of the light waves). The energy of the quantum, for light of $475 \mathrm{~m} \mu$, the blue-green light which penetrates oceanic waters best (Jerlov, 1947-8), is about $4 \times 1 \mathrm{IO}^{-12}$ ergs. Even at the absolute threshold for the human eye when looking at a large field the number of quanta absorbed by the retinal photosensitive pigments is quite large; Denton \& Pirenne give the value of 3000 quanta $/ \mathrm{cm}^{2}$ of retina/sec, a number which leaves a very large margin for improvement in the efficiency of detection. This limit to vision may be set by spontaneous activity in the retina which, to use the jargon of radar, constitutes a 'noise' amongst which the 'signal' of the external light must be detected. Now a likely site of spontaneous activity 
seems to be the spontaneous breakdown (in the dark) of the visual photosensitive molecules within the rods which, since light acts by breaking down the molecules, would give rise to nervous activity of exactly the same type as that given by a dim background light. The rate at which human visual purple would have to break down in the dark in order to be the limiting factor in the detection of light, was calculated as being $0.0005 \% / \mathrm{h}$ by Denton \& Pirenne. We know that in extracts with digitonin it breaks down at the much higher rate of I \% / h (St George, I952), whilst Barlow (1956, I957) has calculated the consequences of the idea that retinal 'noise' sets the limit to visual performance and has, moreover, shown experimentally that many of the predictions of his theory hold good. Reconsidering the possible gain in sensitivity of the deep-sea fish over the human with the idea of retinal 'noise' in mind, we have as before the same advantages because of the greater aperture and greater transparency of eye media, but the extra density of pigment would be much less advantageous because an increase in density is not only accompanied by an increase in signal given by the more effective absorption of the incident light quanta, but also by an increase in 'noise' consequent in the increase in the amount of visual pigment which achieves this extra absorption. The 'noise' will go up as the square root of the density of pigment in the rod and the signal as the fraction of light absorbed. The optimum density of pigment is such that $71.5 \%$ of the light is absorbed (density of 0.55) (Denton \& Pirenne) and then the gain over the human would only be $\times 1 \cdot 25$, not $\times 3$, as simple computation of absorption might suggest. The higher densities found in some deep-sea fish would give an even smaller gain than $\times 1 \cdot 25$ over the human. The deep-sea fish probably has, however, an advantage over man for, with an eye at a lower temperature and a photosensitive pigment which although similar in shape to that of visual purple is displaced towards the blue, the spontaneous rate of breakdown of visual photosensitive pigment might be expected to be much lower. To have an idea of the order of such an effect we may consider, as Stiles (I948) and Barlow (I957) have done, a simplified picture where the molecules of pigment have thermal energies distributed in accordance with Boltzmann's distribution, when a reduction in temperature from the mammalian temperature to that of a deep-sea fish will make the pigment $\times$ Io more stable, whilst the effect of the shift of maxima towards the blue from 502 to $485 \mathrm{~m} \mu$ might be expected to be accompanied by a further tenfold increase in stability. Bridges (1956) finds that in a mixture of two extracted visual photosensitive pigments with maxima at 522 and $533 \mathrm{~m} \mu$ respectively, the first broke down spontaneously in the dark at a rate forty times more slowly than the second (see also Dartnall, 1955).

Thus on the basis of the 'noise' theory allowing for a more stable retina we arrive at a revised estimate of the sensitivity gain of the deep-sea fish eye over the human eye of 60-I20 times instead of I 5-30 times, giving an extra range of vision of daylight of about $40 \mathrm{~m}$ deeper than that calculated above, and 
putting the maximum depth at which the deep-sea fish can see daylight at about II $50 \mathrm{~m}$.

We have not taken account of the possibility of extra physiological summation in area and time in the retinae of deep-sea fish, but the eyes of deep-sea fish are often small and would not permit of much extra area summation over that found in humans, whilst against physiological summation obtained by the absorption of quanta over larger areas and times must be set the possibility of probability summation between independent retinal units. The argument is, however, not a profitable one to pursue because as the intensity of daylight penetrating the ocean falls with depth, the light given by luminescent creatures becomes more and more predominant and no matter how sensitive the eye, the daylight is small compared with this light and the problem is one of intensity discrimination not one of absolute sensitivity. Our estimate of II $50 \mathrm{~m}$ is already down at depths at which this must be true.

We are grateful to Mr N. B. Marshall and Dr W. A. H. Rushton for their advice and help, and to the Director of the National Institute of Oceanography for his kindness in giving permission to carry out experiments aboard R.R.S. Discovery II. We also wish to express our thanks to Captain C. A. Hoodless and the crew of R.V. Sarsia and to Captain S. S. F. Dalgleish and crew of the R.R.S. Discovery II for their enthusiastic co-operation.

\section{SUMMARY}

Measurements were made on the intact retinae dissected from freshly caught deep-sea fish. The unbleached retinae of such fish are not rose-pink like the retinae of most coastal fish or purple like the retinae of most freshwater fish, but are golden in colour.

The golden colours are of photosensitive pigments which give retinal absorption curves similar in shape to frog's rhodopsin, but with maxima of absorption displaced on the average about $15 \mathrm{~m} \mu$ towards the blue end of the spectrum. The names 'chrysopsins' or visual golds are suggested for this group of pigments.

The density of such photosensitive pigments is often very high. Retinal density changes on bleaching of more than $\mathrm{I} \cdot \mathrm{O}$ has been found for several deepsea fish. These probably correspond to absolute retinal densities of pigment of about $\mathrm{I} \cdot 3$, i.e. the absorption of $95 \%$ of blue-green light striking the retina.

The conger and silver freshwater eels have retinae containing similar golden-coloured pigments. These eels begin their lives in the deep ocean and return there when mature to spawn.

The significance of this type of photosensitive pigment in the vision of deep-sea fish is discussed, and an estimate is made of the depths at which deepsea fish will see daylight. 


\section{REFERENCES}

Barlow, H., I956. Retinal noise and absolute threshold. F. opt. Soc. Amer., Vol. 46, pp. 634-9.

- 1957. Purkinje Shift and Retinal Noise. Nature, Lond., Vol. 179, pp. 255-6.

BeEBE, W., I935. Half Mile Down. London: John Lane.

BRIDGES, C. D. B., I956. The visual pigments of the Rainbow trout (Salmo irideus). 7. Physiol., Vol. I34, pp. 620-9.

Clarke, G. L., I936. On the depth at which fish can see. Ecology, Vol. I7, pp. 452-6.

Clarke, G. L. \& Wertheim, G. K., I956. Measurements of illumination at great depths and at night in the Atlantic Ocean by means of a new bathyphotometer. Deep-Sea Res., Vol. 3, pp. I89-205.

Dartnall, H. J. A., I955. Visual pigments of the bleak (Alburnus lucidus). F. Physiol., Vol. I28, pp. 13I-56.

Denton, E. J., I954. Une novelle méthode pour déterminer la courbe d'absorption du pourpre rétinien. C.R. Acad. Sci., Paris, T. 239, pp. 1315-6.

Denton, E. J. \& Pirenne, M. H., I954. The absolute sensitivity and functional stability of the human eye. F. Physiol., Vol. I23, pp. 417-42.

Denton, E. J. \& WALKer, M. A., I957. The visual pigment of the conger eel. (In preparation.)

Denton, E. J. \& WARREN, F. J., I956. Visual pigments of deep sea fish. Nature, Lond., Vol. I78, p. 1059.

Denton, E. J. \& Wyllie, J. H., 1955. Study of the photosensitive pigments in the pink and green rods of the frog. F. Physiol., Vol. 127, pp. 8I-9.

JerLov, N. G., 1947-8. Optical studies of ocean waters. Rep. Swedish deep-sea Exped., Vol. 3, Fasc. I, Physics and Chemistry, pp. I-59.

KüHNE, W., 1878. The Photochemistry of the Retina and on Visual Purple. (Translated by $M$. Foster.) London: Macmillan.

Le Grand, Y., 1948. Lumière et couleurs. Optique Physiologique, Vol. 2. Paris. Editions de la Revue d'Optique.

Marshall, N. B., 1954. Aspects of Deep Sea Biology. London: Hutchinson's.

Rushton, W. A. H., 1956. The rhodopsin density in the human rods. F. Physiol., Vol. 134, pp. 30-46.

St GeORGE, R. C. C., 1952. The interplay of light and heat in bleaching rhodopsin. F. gen. Physiol., Vol. 35, pp. 495-5I7.

STILES, W. S., I948. The physical interpretation of the spectral sensitivity curve of the eye. Transactions of the Optical Convention of the Worshipful Company of Spectacle Makers, 1948, pp. 97-107. London.

WALD, G., 1945-6. The chemical evolution of vision. Harvey Lect., Ser. 4I, pp. $117-60$.

WALD, G., 1938-9. The porphyropsin visual system. F. gen. Physiol., Vol. 22, pp. $775-93$.

\section{Note added in proof}

F. W. Muntz has recently confirmed (Science, I957, Vol. I25, pp. II42-3) that deep-sea fish have golden-coloured retinae. He has also shown that Bathylagus wesethi Bolin has a retinae containing a mixture of two photosensitive pigments. 